\title{
Students' Awareness of Metacognitive Reading Strategies in Academic Reading
}

\section{Dangin ${ }^{1}$}

${ }^{1}$ Universitas Mercu Buana, Yogyakarta, Indonesia

dangin@mercubuana-yogya.ac.id

\section{ABSTRACT}

Being aware of reading strategies becomes the key of readers' success in reading process, this study began with its purpose to investigate the readers' awareness of metacognitive reading strategies while facing academic reading texts. Then, the respondents here were whole 50 students of English department, who had completed the questionnaire of Survey of Reading Strategies Awareness (SORS). Those respondents were intended to reveal the type of reading strategies used during reading academic materials in English. The results of study revealed that those respondents were aware of using two of three categories of reading strategies while reading the materials. As the detail, the results showed that the respondents mostly tended to use the strategies categorized in Problem Solving Strategies (PROB) to solve their obstacle in reading. Global Reading Strategies (GLOB) as second place, which is mostly used by the respondents. And the last or the lowest strategies in use are Support Strategies (SUP).
KEYWORDS:

Academic reading, metacognitive reading, students' awareness, survey of reading.

\section{Introduction}

Reading can be described as an interactive cognitive process in which readers interact with text (Yuksel \& Yuksel, 2012). While in reading process, the readers consciously or unconsciously tend to frame and predict the information that will come by using their own strategies and knowledge of language in order to arrange the meaning. Those strategies can be described as the way the readers to manage their interaction with written text, to make reading more effective and to improve comprehension (Singhal, 2001)

Moreover, Metacognitive reading strategy becomes one of crucial aspects for learners in comprehending the academic reading text. Ahmadi, et al (2013) say that reading comprehension refers to the ability of readers to understand the 
surface and the hidden meanings of the text using metacognitive reading strategies. Readers' perception in monitoring and regulating of these strategies during reading are called as readers' awareness (Anderson, 2003). The awareness of metacognitive reading strategies influences learners comprehension because it controls the ways learners arrange their interaction with the context and also for how the use of strategies is related to effective reading comprehension (Mokhtari \& Sheorey, 2002). In addition, Barker and Brown (1980) also say that the metacognitive aspects of reading for remembering include identifying important ideas, predicting and making hypothesis of the exact information of material, developing effective study strategies and allocating study time appropriately. Thus, metacognitive reading strategies herein take a significant role as the controller of learners' interaction toward the text. In order to reach the description of metacognitive reading strategies use, the researcher addresses research question about to what extent the level of students' awareness of metacognitive reading strategies use in academic reading.

A number of studies have been conducted in investigating students' awareness revealed a positive relationship between metacognitive reading strategies use and reading comprehension (Gaith \& El-Sanyoura, 2019). It come up with the findings that the use of metacognitive reading strategies has significant role when the students interacting with printed materials. Regarding that findings, it is believed that understanding students' awareness will help them to improve their performance. One of the most essential skills that classroom teachers can help second language learners' development is understanding or controlling cognitive processes (Anderson, 2002). It is important to teach the students metacognitive skills in addition to cognitive skills.

\section{Metacognitive strategies}

Metacognition refers to how cognition deals with strategy and knowledge. It alludes to the knowledge and control that we have over our cognitive processes. It also includes awareness and control of the students in planning, repairing, monitoring, revising, summarizing and evaluating. Additionally, Davis (2011) states that metacognition is cognition about cognition that commonly referred to as thinking about thinking and it is having an awareness of and an understanding 
about your own cognition. Hence, it is assumed that metacognition takes a role for enabling students to get to be aware about what topic they should think, what strategies they should use and how to evaluate their performance. In other words, metacognition underpins all effective learning for the students, especially in reading in this case.

Metacognitive reading strategies encourage students to work their cognitive knowledge and compose an effort to integrate their learning by means of planning, monitoring, and evaluating. In addition, Zhang \& Seepho (2013) mention that in reading context, metacognitive strategies uplift students to do selfmonitoring and self-regulating activities and focus on both the process and the product of reading. Moreover, to successfully conquer the complexity of reading materials, the readers should be able to employ metacognitive knowledge and should adduce conscious and think about the strategies. Metacognitive knowledge of the readers here includes awareness a variety of reading strategies and of the fact that metacognitive awareness of reading strategies influences cognitive enterprise of reading (Kabalaei, 2011). There are differences between metacognitive knowledge, which refers to the knowledge of cognitive and metacognitive skills, which are defined as regulation of cognition. Jacob and Paris (1987) divide metacognition into two broad categories: metacognitive knowledge that refers to self-appraisal of cognition and metacognitive control process that refers to self-regulated thinking.

As mentioned before, metacognitive knowledge alludes to self-appraisal of cognition. Based on Jacob and Paris (1987), it consists of three broad subcategories that refer to as; declarative knowledge (knowledge about information of individual knowledge as learner and about affecting components toward learners' performance. It refers to what is known in propositional manner. For instance, a learner could know that topic familiarity and prior knowledge influence reading speed and comprehension or that rereading facilities memory), procedural knowledge (an awareness of process of thinking. It is defined as knowledge about implementation of procedural skills. It leads the learner to use procedural skills automatically, becoming more sequence in using the strategies, and solve the problems effectively. For instance, a student could know how to 
skim, how to use context, how to underline, how to summarize, and how to find the min idea while reading), and conditional knowledge (knowing how to do things. It refers to awareness of the conditions that influence learning such strategies are effective, when they should be applied and when they are appropriate. As an illustration, students can become aware of the value of periodic paraphrasing as a means for monitoring comprehension, yet they also need to realize that paraphrasing is a strategy used selectively for some purposes with some type of text).

\section{Management Skills of Metacognitive Reading Strategies}

Management skills have relevance to the regulatory process for operating the strategies. Jacobs and Paris (1987) also provide management skills of metacognitive reading strategies into three essential skills as follows; planning (The students make a preview what reading material will be about. They also forecast those upcoming materials by using previous knowledge or experience. It refers to the selective coordination of a cognitive means to a cognitive goal. For example, making predictions before reading, strategy sequencing, and allocating time or attention selectively before beginning a task (Ahmadi, 2013)) , monitoring (The readers use the strategies to analyze the information as a project progresses. It is aimed to increase the effectiveness and efficiency of reading activities. It also refers to individual awareness of using strategies while facing written text. Selfmonitoring thinking requires an individual to monitor some progresses and then revise or modify plans and strategies depending on how well they are working. It also allows the reader to regulate or rearrange the step based on the needs), and evaluation (The process of appraisement in what the readers have conducted. The readers assess their work in order to look over the difficulties or obstacles faced in reading activities. For instance, readers can evaluate their own understanding as they pause, paraphrase, answer question, or summarize the information in text).

Therefore, by understanding those management skills, the instructor or teacher in this scope can promote the numbers of strategies as the effort to increase learners understanding in reading comprehension. Thus, the researcher believes that by emphasizing those regulator processes (planning, monitoring, and evaluation), the readers can be more aware of their reading procedure rather than 
read without strategies. It can be the ways to reach great comprehension by involving cognitive resources such as attention, better employment of strategies, and a greater awareness of comprehension breakdown.

\section{Significance of Metacognitive Reading Strategies}

As mentioned before, that metacognitive reading strategies are the conscious strategies by which the students monitor their own reading process covering evaluation of the effectiveness of cognitive strategies being used. If cognitive reading strategies are about having knowledge of what strategy to use and how it is applied, for further metacognitive strategic knowledge involves understanding the rationale to apply a particular strategy in a particular context, and evaluate its usefulness in terms of appropriateness and effectiveness for that context. Thus, it can be conclude that in its relation with cognitive strategies, metacognitive reading strategies become the strategies that help students to regulate or monitor their cognitive strategies. Metacognitive reading strategy awareness, are strategies that help students to regulate or monitor cognitive strategies (Ahmadi, 2013). Metacognitive strategies are ordered processes used to control one's own cognitive activities and to ensure that a cognitive goal (for example, solving a math problem, writing an effective sentence, understanding reading material) have been met (Flavell, 1979). Therefore, metacognitive strategies herein are designed to monitor cognitive progress.

\section{Method}

The respondents of this study were 50 Indonesian undergraduate students enrolled at English Language Studies. Those respondents were required to pass English Proficiency test. Thus, it was believed that the respondents herein were advanced learners of EFL and were able to use a number of strategies while reading the academic texts.

In this study, in order to gain the data of respondents' awareness of metacognitive reading strategies used while interacting with academic texts, the Survey of Reading Strategies (SORS) initiated by Mokhtary and Sheory (2002), was adopted. Metacognitive reading strategies are divided into three categories, these categories include; Global Reading Strategies (GLOB) (Intentional, carefully 
planned techniques by which learners monitor or manage their reading, such as having a purpose in mind, previewing the text as to its length and organization, or using typographical aids and tables and figures (13 items)), Problem Solving Strategies (PROB) (The action and procedures that readers use while working directly with the text. These are localized, focused techniques used when problems develop in understanding textual information; examples include adjusting one's speed of reading when the material becomes difficult or easy, guessing the meaning of unknown words, and rereading the text to improve comprehension (8 items)), and Support Strategies (SUP) (basic support mechanisms intended to aid the reader in comprehending the text such as using a dictionary taking a notes, underlining, or highlighting textual information (9 items)).

This questionnaire consists of 30 items ( 13 items for GLOB, 8 items for PROB and, 9 items for SUP), which each item is labeled a five-point Likert scale ranging from 1 for "never do" to 5 for "always do"(Sullivan \& Artino Jr, A, 2013). They also provided a key to interpret the mean for each item and overall item ratings of the SORS. They considered a mean $\leq 2.4$ as low usage, $2.5-3.4$ as medium usage, and $\geq 3.5$ as high usage. The same rating is also used in interpreting the result beside. The range intervals indicating the frequency of strategy use from Always to Never were calculated for the data collection instrument (SORS).

In order to get the data analysis display, SPSS. 20 was used to work with descriptive statistical procedures. The mean values and standard deviation values were gained to discuss the use of metacognitive reading strategies, frequency of use, and the use based on categories.

\section{Findings}

\begin{tabular}{|c|c|c|c|}
\hline & N & Mean & Std. Deviation \\
\hline GLOB & 13 & 3.6764 & .27131 \\
\hline PROB & 8 & 3.7232 & .34875 \\
\hline SUP & 9 & 3.2698 & .40213 \\
\hline Overall & & 3.5565 & \\
\hline
\end{tabular}


Table 1. Descriptive statistics of metacognitive reading strategies use

The table shows the overall use of metacognitive reading strategies and the mean value of the three categories of metacognitive reading strategies. It reveals the overall mean value $(M=3.56)$ that indicates the respondents are aware in using metacognitive reading strategies during reading academic text. Meanwhile, in categorical use, the usage of problem-solving strategies (PROB) was reported as the highest frequent strategies that the respondents preferred to use for academic reading with mean value $(M=3.72, S D=.35)$.

Almost similar to the highest one, global strategies (GLOB) placed in second spot with mean value $(M=3.68, S D=.27)$. However, support-reading strategies (SUP) was outlined as it came to be the lowest in usage with mean value $(M=3.27$, $S D=.40$ ). Afterwards, the findings will be discussed later on following discussion section.

\section{Discussion}

The findings show that Problem Solving Strategies (PROB) with its highest usage the readers are aware in using strategies while reading. These findings are also in accordance to the previous study by Lian Zhang \& Sirinthorn Seepo (2013), Yuksel \& Yuksel (2012), Joel Magogwawe (2016), and Ahmad Alhaqbani \& Mehdi Riazi (2012).

The readers here prefer using the problem solving strategies; it can be seen from the data that shows mean values as $(M=3.72, S D=.35)$. Then, these readers are generally aware of their reading process and capable in taking action during reading in order to solve or overcome the readings problems or difficulties. For example, the items within this strategy are such as "when the reading becomes difficult, I take more attention to what I am reading". It means that they are consciously realize that when they are facing the difficulties, they can or have to give closer attention toward the reading. Also strategy like "when texts become difficult, I re read it to get more understanding". It can be drawn that the readers here tend to use the strategy by rereading the text in order to respond the stuck circumstance, which is caused by the obstacle in text. Another strategy is such "I try to get back on track when I lose concentration", it demonstrates the students' awareness of their reading comprehension process and the strategies they applied 
to address any reading problems. Thus, what does it mean? It indicates that the readers are consciously sensitive in breaking those obstacles while reading. Baker \& Brown (1984, p.32) argue that the use of problem-solving strategies is associated with skilled reading and that good readers use these strategies to enhance and regulate their reading comprehension.

The placement of GLOB into second most preferred category $(M=3.68, S D=$ .27) could be clarified as the indication of readers' tendency to manage and plan their reading comprehension process. These strategies consist of 13 items that one of them could be in form such "I have a purpose in mind when I read". It can be a sign that the students are aware of the main aims of reading that are getting information or learning process, pleasure, and survival (Wallace: 2003, p. 96). It means the readers are aware that the previous or background knowledge have significant role in assisting their understanding the reading. But, herein, those 13 items are not among the most favored strategies within the subcategory of GLOB strategies. In other words, the readers may not only have recognized the need for using planning and monitoring strategies but also have uncertain knowledge of how to employ or apply them in the proper circumstances during the reading process. When readers reflect upon their reading strategies, they become better prepared to make conscious decision about what they can do to improve their learning (Anderson, 2002).

The choice of SUP into third or the lowest place in the usage indicates that the readers here tend to ignore the aspect of reading which can help them in gaining the information within the reading. Along with that lowest average in usage as $(M=3.27, S D=.40)$, these choices also describe that the readers consciously or unconsciously do not consider the supporting items that could be an obstacle in their reading process. Herein, however, the readers cannot be successful in reading if they do not realize that reading process needs those supporting strategies. In accordance to Mokhtarin and Shoerey (2002), these strategies becomes the basic support mechanisms intended to aid the readers in comprehending the text. 


\section{Conclusion}

This conclusion is supported by the fact that most of the problem-solving strategies were ranked above higher than global strategies. It can be concluded that this group of readers indicated the ability to fix comprehension problems through various strategies. Yet, it can be construed that they are skilled readers depends on many other aspects, including high usage of global reading strategies, which was found in this study. On the other hand, considering that graduate students' reading materials here are about practical theories and of course it needs high motivation and proper strategies toward those readings, hereby, the researcher would like to suggest the readers themselves to keep their habits in using first two strategy (PROB \& GLOB) and also to be more aware in their supporting strategies (SUP) because this strategies also will decide their success in gaining the information within the reading materials. As if, however, if the reader is not aware of his or her own limitations as a reader or of the complexity of the task at hand, then the reader can hardly be expected to take actions to anticipate or recover from difficulties. The reason for why those strategies should get high usage is because the reading strategies are the key to succeed in reading itself. It might be that reading for study or any academic purpose stimulates readers to use more strategies, as reading academic texts makes greater cognitive demands.

\section{References}

Ahmadi, E. a. (2013). The Importance of Metacognitive Reading Strategy Awareness in Reading Comprehension (Vol 10). English Language Teaching/ Canadian Center of Science and Education.

Anderson. (2003). Scroling, clicking and reading.

Anderson, N. J. (2002). The role of metacognition in second/foreign language teaching and learning. ERIC Digest. Washington, DC: ERIC Clearinghouse on Languages and Linguistics.

Barker, L., \& Brown, A. L. (1980). Metacognitive Skills and Reading: Technical Report No. 188. Washington, DC: Beranek and Newman.Inc.

Davis, A. (2011). Building comprehension strategies: for the Primary Years. Hong Kong: Eleanor Curtain Publishing.

Flavell, J. . (1979). Metacognition and cognitive monitoring: A new area of cognitive-developmental inquiry. American Psychologist, (34), 906-911.

Gaith, G., \& El-Sanyoura, H. (2019). Reading Comprehension: The Mediating Role of Metacognitive Strategies. Reading in a Foreign Language. 
Jacobs, J. ., \& Paris, S. . (1987). Children's Metacognition About Reading. Issues in Definition, Measurement, and Instruction. Educational Psychologist, 22, 255278.

Kabalaei, A. (2011). Metacognition and Reading Comprehension. Ikala, Revista de Lenguaje y Cultura, 16, 5-14.

Magogwe, J. M. (2016). Metacognitive Awareness of Reading Strategies of University of Bostwana English as Second Language Students of Different Academic Reading Proficiencies. Reading \& Writing, 4(1). https://doi.org/http://dx.doi.org/10.4102/rw.v4i1.29

Mokhtari, K., \& Sheorey, R. (2002). Measuring ESL students" awareness of reading strategies. Journal of Developmental Education.

Singhal, M. (2001). Reading Proficiency, Reading Strategies, Metacognitive Awareness and L2 Readers. Retrieved from http://www.readingmatrix.com/articles/singhal/

Sullivan, G. ., \& Artino Jr, A, R. (2013). Analyzing and Interpreting Data from LikertType Scales. Journal of Graduate Medical Education, 5(4), 542.

Yuksel, I., \& Yuksel, I. (2012). Metacognitive Awareness of Academic Reading Strategies. Turkey: Elsevier Ltd.

Zhang, L., \& Sheepo, S. (2013). Metacognitive Strategy Use and Academic Reading Achievement: Insights from a Chinese Context. Electronic Journal of Foreign Language Teaching, 10, 54-69. 